\title{
Article \\ Deformation Characteristics of Raising, Widening of Old Roadway on Soft Soil Foundation
}

\author{
Keke Li ${ }^{D}$, Wenyuan $\mathrm{Xu}$ * and Liang Yang \\ School of Civil Engineering, Northeast Forestry University, Harbin 150040, China; likeke@nefu.edu.cn (K.L.); \\ yangliang@nefu.edu.cn (L.Y.) \\ * Correspondence: xuwenyuan@nefu.edu.cn
}

Citation: Li, K.; Xu, W.; Yang, L. Deformation Characteristics of Raising, Widening of Old Roadway on Soft Soil Foundation. Symmetry 2021, 13, 2117. https://doi.org/ $10.3390 /$ sym 13112117

Academic Editor: Laura Bulgariu

Received: 12 October 2021

Accepted: 5 November 2021

Published: 8 November 2021

Publisher's Note: MDPI stays neutral with regard to jurisdictional claims in published maps and institutional affiliations.

Copyright: (c) 2021 by the authors. Licensee MDPI, Basel, Switzerland. This article is an open access article distributed under the terms and conditions of the Creative Commons Attribution (CC BY) license (https:/ / creativecommons.org/licenses/by/ $4.0 /)$.

\begin{abstract}
The deformation characteristics of a raised and widened old Chinese roadway on a soft soil foundation are investigated in this study via finite element numerical simulation. The rules of ground surface settlement, slope foot lateral displacement, and ground surface settlement evolution of the roadbed under three modes (one-time construction of an eight-lane expressway, widened four-lane expressway, and raised/widened four-lane expressway) are compared. The ground surface settlement process of the eight-lane road foundation, which is formed by first widening and then raising the road, is highly complex. The ground surface settlement curve under the old road foundation increases and then decreases. The lateral displacement of the slope foot also interacts with the widening and raising of the eight-lane roadbed foundation. The range of lateral displacement is $70.05,42.58,124.81,104.54 \mathrm{~mm}$. Fifteen years after construction, the total settlement of the raised and widened roadbed is much larger than that of the one built directly. The total settlement values at the center of the two roadbeds are 297.05 and $234.85 \mathrm{~mm}$, respectively. This manuscript provides data support for the reconstruction and expansion of roads on soft soil foundations, for choosing appropriate construction methods to build roads, and for avoiding major road damage, which is of great significance to the construction of road infrastructure in the future.
\end{abstract}

Keywords: finite element; soft soil foundation; widening of existing road; deformation characteristics; settlement

\section{Introduction}

Since the 70th anniversary of the founding of the People's Republic of China, there have been dramatic changes surrounding the development of cities and the construction of new rural areas. Roadways built many years ago do not satisfy modern traffic demands. New expressways have been developed by rebuilding and extending original roads to satisfy these demands [1] After years of operation, old roadbeds have been consolidated significantly and thus show significantly different settlement characteristics compared to new roadbeds. The variations in settlement between old and new roadbeds create longitudinal cracks in the widened pavement, which can seriously threaten public transportation safety [2-5]. Figure 1 shows typical pavement distress occurring after the widening of roadways.

El Kamash [6] used a two-dimensional difference numerical method to analyze the widened column-supported embankment on soft soil in the context of roadbed widening. Van Meurs [7] conducted a field study on the gap method for embankment widening. Forsman and Uotinen [8] studied the effect of geosynthetics on subgrade settlement. Masaki Kitazume and Kenji Maruyama [9] investigated the external stability of a group column type DM with improved ground under embankment loading. Kenji Watanabe [10] proposed that a combination of deep mixing wall foundation improvement and cement mixing of crushed stone can effectively reduce embankment and surrounding foundation deformation. 


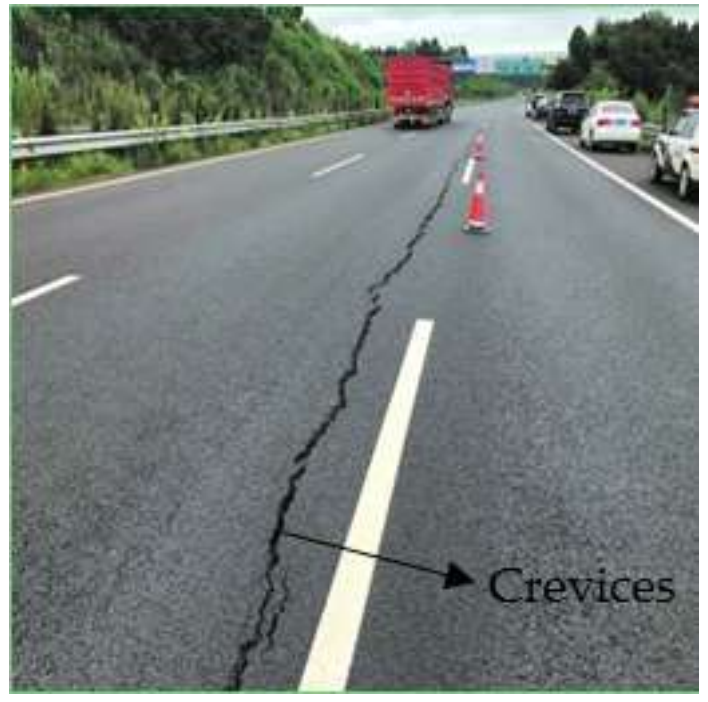

(a)

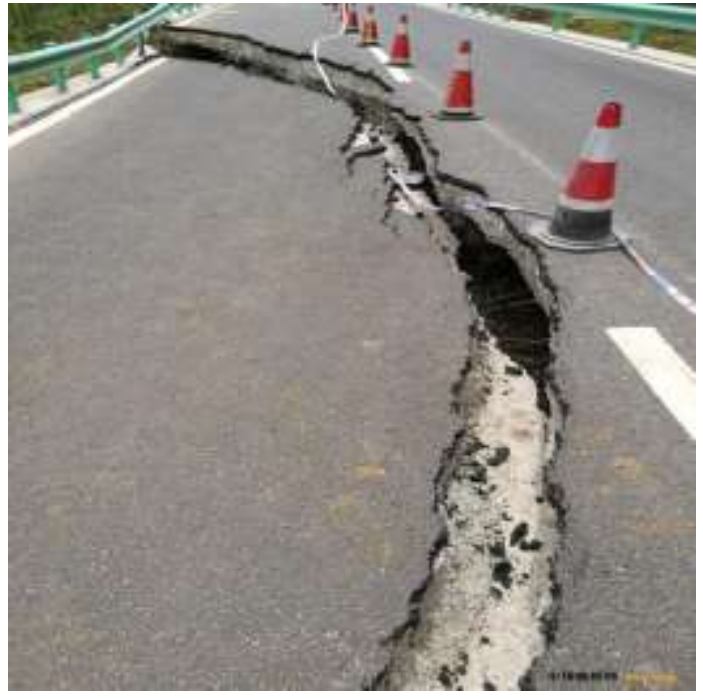

(b)

Figure 1. Pavement distress after roadway widening. (a) Longitudinal crevices of subgrade; (b) subgrade instability.

According to Ozer [11], the structure of geofabric blocks can significantly improve the performance of traditional edge hill widening technology under seepage force. Phutthananon [12] found that the effect of soft soil layer thickness on differential settlement is not significant, but on average, settlement is significant; the effect of pile strength on differential settlement is significant only when the pile cap size is relatively small. Miao [13] examined the effect of geogrid reinforcement on widening with differential settlement. Jiang [14] used the finite element method to simulate two-side symmetric widening, twoside asymmetric widening, one-side widening, and split-side widening before comparing the potential slip surface morphology, stability factor of safety, excess pore water pressure, vertical displacement, and lateral displacement among the four widening modes. Jiang did not discuss the displacement of the foundation and the roadbed under different construction methods. Other scholars [15] have used small-scale centrifuges to examine the influence of construction methods on road widening affecting soft soil foundations.

Jia [16] discussed the factors that cause differing settlement between old and new roadbeds in the reconstruction and extension of highways. Ja [17] analyzed the effects of additional stress on an old embankment. Based on the Mohr-Coulomb model, the settlement and deformation laws of the old embankment and the widened embankment were compared with actual physical measurements. Zhang [18] investigated the deformation characteristics and differential settlement standards of a roadbed in an expressway widening project with a soft soil foundation. Fu [19] analyzed the influence of different differential settlement on the additional stress of each layer of a pavement structure with a finite element analysis model and proposed a differential settlement control standard considering the structural and functional requirements of the pavement. Based on the treatment of new and old subgrades in a typical expressway section, the relationship between the differential settlement of new and old subgrade and pavement stress was analyzed by $\mathrm{Pu}$ [20].

$\mathrm{Lu}$ [21] proposed a maximum allowable differential settlement of $5.44 \mathrm{~cm}$ for an integrated pavement structure. Zhang [22] explored the reconstruction project of the Yan'an North Transit Line to analyze the differential settlement characteristics of the widened subgrade, the control standard of differential settlement for subgrade widening, and the rationality of wet and soft ground treatments via numerical simulation and field test section monitoring. Wei [23] examined the interaction between an old and new roadbed to determine the settlement law of the roadbed by numerical simulation.

In the course of reconstruction and extension, existing roadways are affected by the necessary adjustment of the route longitudinal slope index and the increase in the headroom for bridges and culverts $[24,25]$. The deformation characteristics throughout the process of 
road raising and widening must be properly understood to ensure safety. Previous studies on roadbed widening have mainly centered on comparing the mechanical behaviors of different widening methods, the influencing factors of the differential settlement of new and old roadbeds, and the differential settlement control standards for new and old roadbeds. There have been relatively few studies, however, on ground surface settlement evolution rules or variations in ground surface settlement between old and new roadbeds-particularly in terms of how these factors are also affected by different construction modes. The roadbed of an eight-lane expressway with two-way traffic has unique deformation characteristics due to the inherent difference between the two construction methods of directly constructing and widening. Various widening methods also cause differences in subgrade deformation characteristics [26]. Uneven settlement is mainly caused by the soft soil in the roadbed [27]. On the basis of previous studies, the deformation characteristics of a soft soil foundation throughout the raising and widening process of an old roadway were analyzed in this study. This manuscript provides data support for the reconstruction and expansion of roads on soft soil foundations, choosing appropriate construction methods to build roads, avoiding major road damage, and having great significance for the construction of road infrastructure in the future

\section{Materials and Methods}

\subsection{Analysis of Deformation Characteristics of Subgrade by Finite Element Method}

The differential settlement of new and old roadbeds caused by roadway widening is affected by many factors that are difficult to integrate into a theoretical calculation. The finite element software ABAQUS was used here for a simpler and less cumbersome numerical analysis of the settlement characteristics of new and old roadbeds.

In 2006, Zhang analyzed simulated and observed settlement values of key roadbed sections in experimental sections of the Shanghai-Nanjing expressway widening and reconstruction project, where the test results and theoretical results obtained in ABAQUS were in accordance. In 2014, Zheng [28] monitored the vertical displacement of new and old road shoulders, as well as the lateral displacement of new and old road shoulders in the process of widening a roadbed. They used ABAQUS to simulate the construction process according to the actual conditions. ABAQUS finite element software is applicable to widening road displacement analysis and prediction work.

\subsection{Numerical Calculation Model}

\subsubsection{Geometric Model}

After the four lane is rebuilt and expanded to form an eight lane, due to the different degrees of consolidation of the old and new subgrades after the road enters the operation process, the old and new subgrades will have differential settlement, and the pavement structure layer will be subjected to tensile stress. With the gradual increase of differential settlement, the tensile stress received by the pavement structure layer will gradually increase, and the pavement will eventually be destroyed and longitudinal joints will be formed, as shown in Figure 1a. When constructing a new subgrade, if the compaction of the new subgrade is insufficient or the soft soil under the subgrade is not effectively treated, the new subgrade will be unstable, as shown in Figure 1b. Therefore, it is necessary to analyze the settlement of new and old roadbeds after reconstruction and expansion.

Many years ago, most of the expressways built in China were four-lane highways. Eight-lane highways are now the norm. The "newly built" roadbed discussed in this paper is a two-way, eight-lane highway with $42 \mathrm{~m}$ width and $8 \mathrm{~m}$ height ("Plan $\mathrm{A}^{\prime \prime}$ ) as shown in Figure 2. The widening and reconstruction of the eight-lane expressway was completed by two distinct approaches. The first approach uses a two-way, four-lane highway with a $28 \mathrm{~m}$ wide and $8 \mathrm{~m}$ high roadbed surface to form a two-way, eight-lane, symmetrically spliced roadway ("Plan B"), as shown in Figure 3. The second approach begins with a two-way, four-lane highway with a $28 \mathrm{~m}$ wide and $4 \mathrm{~m}$ high roadbed that is filled from $4 \mathrm{~m}$ to $8 \mathrm{~m}$ to form a two-way, eight-lane roadway ("Plan C"), as shown 
in Figure 4. It is assumed here that the foundation consists of $12 \mathrm{M}$ mucky clay and $8 \mathrm{M}$ silty clay with a water level $1 \mathrm{~m}$ below the surface. The slope gradient of the new and old roadbed is 1:1.5. Due to its symmetry, the center of the old road can be taken as half of the symmetry plane of the structure.

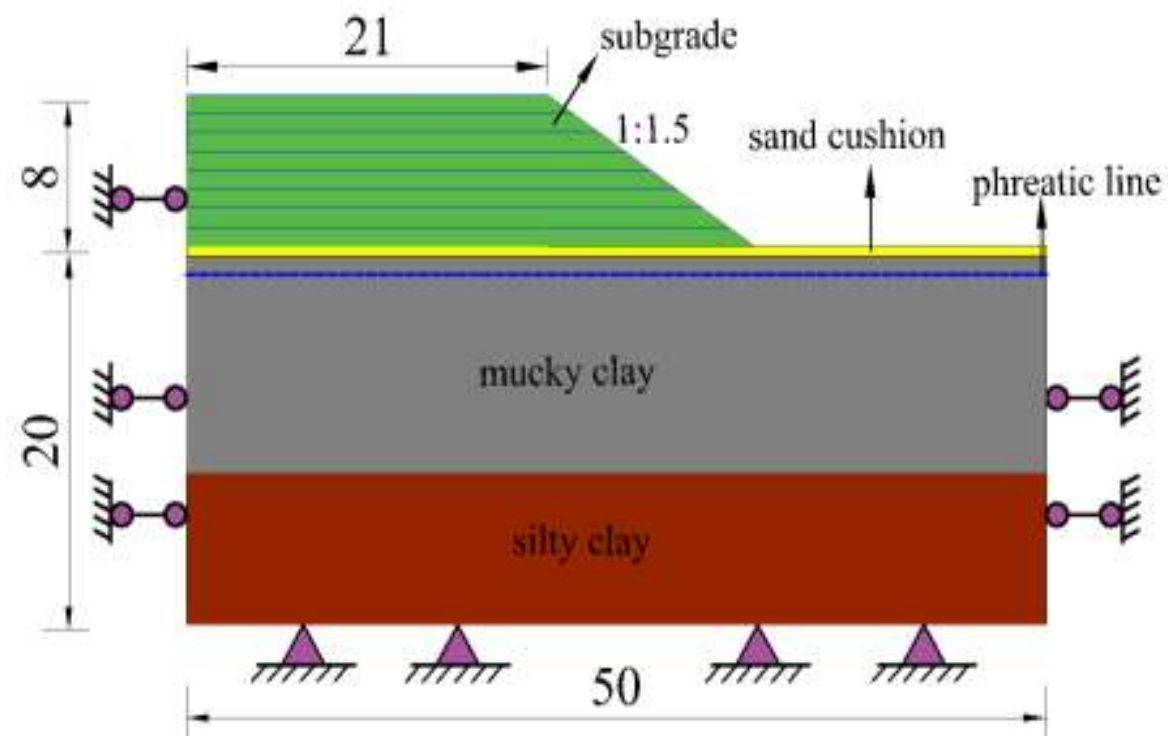

Figure 2. Plan A.

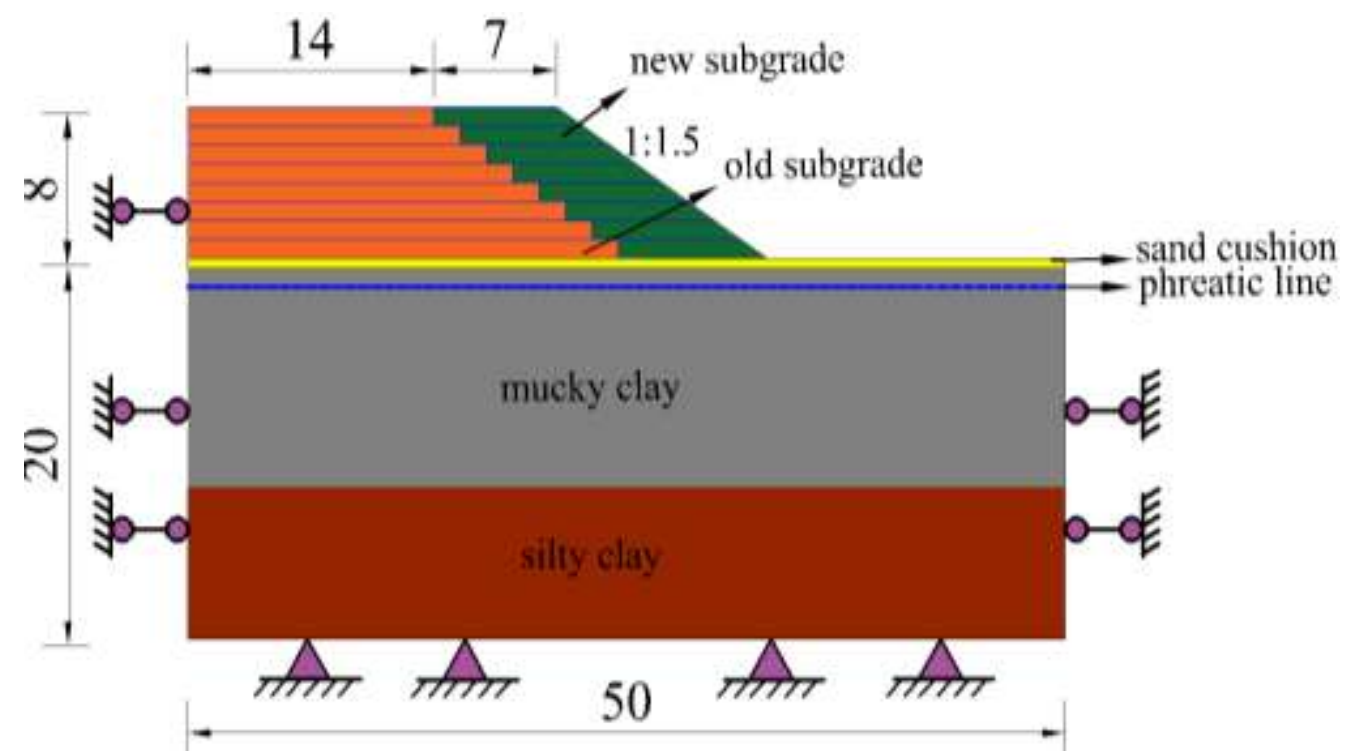

Figure 3. Plan B. 




Figure 4. Plan C.

\subsubsection{Material Constitutive Model and Parameters}

Considering the complexity of highway reconstruction and expansion, this article assumes the following conditions when conducting finite element analysis:

(1) Various soil materials are regarded as homogeneous, continuous, and isotropic elastoplastic bodies, with continuous contact between layers and complete adhesion.

(2) The old roadbed and the widened roadbed will not slip and detach relative to each other during the deformation process, the contact surface is handled well, and the contact is completely continuous.

(3) In the calculation, different constitutive models are used for different materials to reflect the difference of material stress and strain response. The soil itself has a high degree of nonlinearity, and the linear elastic model has a large error. In this paper, a modified Cambridge model (Clay plasticity) is used to simulate the underlying silty clay, and the embankment and silty clay are ideally based on Drucker-Prager (DP), an elastic-plastic constitutive model.

The subgrade is $8 \mathrm{~m}$ high, and the Drucker-Prager (D-P) elastic-plastic model is adopted. The subgrade bottom is $0.5 \mathrm{~m}$ thick with sand cushion and the permeability coefficient is $1.0 \mathrm{~m} / \mathrm{d}$. The soft soil foundation is composed of two types of soil: muddy clay and silty clay. The D-P elastoplastic model was adopted for muddy clay with a permeability coefficient of $0.00012 \mathrm{~m} / \mathrm{d}$. The clay-plasticity model was used for silty clay with a permeability coefficient of $0.00006 \mathrm{~m} / \mathrm{d}$. The water table is located $1.5 \mathrm{~m}$ below the base of the roadbed. Other material parameters are listed [29] in Tables 1-4 [30].

Table 1. D-P model parameters. (Reprint with permission [Application of Abaqus Finite Element Software in Road Engineering, 2rd ed]; 2014, University Press: Nanjing).

\begin{tabular}{ccccccccc}
\hline $\begin{array}{c}\text { Material } \\
\text { Type }\end{array}$ & $\begin{array}{c}\gamma_{\mathbf{d}} \\
\left(\mathbf{K N} / \mathbf{m}^{3}\right)\end{array}$ & $\begin{array}{c}\mathbf{C} \\
(\mathbf{K P a})\end{array}$ & $\begin{array}{c}\boldsymbol{\Phi} \\
\left.\mathbf{(}^{\circ}\right)\end{array}$ & $\begin{array}{c}\mathbf{E} \\
(\mathbf{K P a})\end{array}$ & $\boldsymbol{\mu}$ & $\boldsymbol{\beta}\left(^{\circ}\right)$ & $\boldsymbol{K}$ & $\boldsymbol{\psi}\left(^{\circ}\right)$ \\
\hline $\begin{array}{c}\text { Embankment } \\
\text { filling }\end{array}$ & 18.3 & 29.3 & 36.5 & 20,000 & 0.4 & 0.4 & 28.7 & 28.7 \\
Mucky clay & 17.6 & 8.0 & 24.0 & 2500 & 0.35 & 0.35 & 35.3 & 35.3 \\
\hline
\end{tabular}


Table 2. Hardening parameters of D-P model. (Reprint with permission [Application of Abaqus Finite Element Software in Road Engineering, 2rd ed]; 2014, University Press: Nanjing).

\begin{tabular}{cccc}
\hline \multicolumn{2}{c}{ Embankment Filling } & \multicolumn{3}{c}{ Mucky Clay } \\
\hline $\begin{array}{l}\boldsymbol{\sigma} \mathbf{1 - \sigma 3} \\
\mathbf{K P a})\end{array}$ & $\boldsymbol{\varepsilon p}$ & $\begin{array}{c}\boldsymbol{\sigma 1 - \sigma 3} \\
\mathbf{( K P a )}\end{array}$ & $\boldsymbol{\varepsilon} \mathbf{p}$ \\
\hline 170.1 & 0.000 & 57.04 & 0.000 \\
649.9 & 0.035 & 102.359 & 0.0082 \\
740.3 & 0.050 & 177.59 & 0.024 \\
801.4 & 0.073 & 282.18 & 0.056 \\
848.0 & 0.091 & $/$ & $/$ \\
\hline
\end{tabular}

Table 3. D-P model parameters. (Reprint with permission [Application of Abaqus Finite Element Software in Road Engineering, 2rd ed]; 2014, University Press: Nanjing).

\begin{tabular}{cccccccccccc}
\hline $\begin{array}{c}\text { Material } \\
\text { Type }\end{array}$ & $\begin{array}{c}\gamma_{\mathbf{d}} \\
\left(\mathbf{K N} / \mathbf{m}^{3}\right)\end{array}$ & $\begin{array}{c}\mathbf{C} \\
(\mathbf{K P a})\end{array}$ & $\begin{array}{c}\boldsymbol{\Phi} \\
\left({ }^{\circ}\right)\end{array}$ & $\kappa$ & $\boldsymbol{v}$ & $\boldsymbol{\lambda}$ & $\mathbf{M}$ & $\begin{array}{c}\boldsymbol{\alpha}_{\mathbf{0}} \\
\left(\mathbf{N} / \mathbf{m}^{2}\right)\end{array}$ & $\boldsymbol{\beta}$ & $\mathbf{K}$ & $\mathbf{e}_{\mathbf{1}}$ \\
\hline Silty clay & 17.8 & 22.4 & 31.6 & 0.0 .2 & 0.31 & 0.07 & 1.27 & 0.00 & 1.00 & 1.00 & 1.02 \\
\hline
\end{tabular}

Table 4. Parameters of sand cushion model.

\begin{tabular}{ccccc}
\hline $\begin{array}{c}\text { Material } \\
\text { Type }\end{array}$ & $\begin{array}{c}\gamma_{\mathrm{d}} \\
\left(\mathbf{K N} / \mathbf{m}^{3}\right)\end{array}$ & $\begin{array}{c}\mathrm{E} \\
(\mathbf{K P a})\end{array}$ & $\boldsymbol{\mu}$ & $\begin{array}{c}\mathbf{D} \\
(\mathbf{m})\end{array}$ \\
\hline sand & 20 & 50 & 0.3 & 0.5 \\
\hline
\end{tabular}

\subsubsection{Boundary Conditions, Initial Conditions, Construction Procedures}

The left and right sides of the foundation are subject to horizontal constraints and the bottom is subject to horizontal and vertical constraints. To realistically simulate the roadbed filling process $[30,31]$, the finite element simulation began with layered roadbed filling. For a one-off new two-way eight-lane highway, four-lane widening was conducted to form a two-way eight-lane highway; the roadbed was constructed via layered filling method. The subgrade of the new, two-way, eight-lane highway was divided into eight layers of equal thickness $(1 \mathrm{~m})$. The filling time was $30 \mathrm{~d} /$ layer, and the construction interval was $30 \mathrm{~d}$. For the two-way, eight-lane road subgrade, which is comprised of dual two-way, four-lane sides, the construction procedure of the old roadbed was the same as that of the one-time, newly built, two-way, eight-lane road subgrade. The new roadbed was constructed three years after the old roadbed had been completed. The two-way, eight-lane roadbed was divided into four layers of equal thickness $(1 \mathrm{~m})$ and the new roadbed was built step-by-step after the old roadbed was completed. When the new roadbed and the old roadbed reached the same height, the whole embankment was filled with four $1 \mathrm{~m}$ layers of soil to form a two-way, eight-lane highway. Figure 5 shows the finite element mesh diagram of the subgrade.

When using the ABAQUS finite element program to simulate the construction process, it is necessary to control the state of the unit according to the actual situation in order to better simulate the development process of embankment stress and strain during layered filling. The specific method is to use the time step command in ABAQUS to control the hierarchical loading of the embankment, divide the embankment into 8 layers for incremental analysis, and each layer has a thickness of $1 \mathrm{~m}$ and a filling rate of $1 \mathrm{~m} / 30$ day. The intermittent period of construction after each layer is filled is one month. The method of loading in ABAQUS: After completing the model, add "*Model Change, Remove" in the analysis step to remove the corresponding unit, and add "Model Change, Add" in the subsequent step to add the corresponding unit. Set each level of load to correspond to the time step. At each time step, if a load is applied, the corresponding grid unit is activated, 
and the corresponding time step simulates the application of the self-weight stress; if no load is applied, the corresponding time step simulates the construction intermittent period to simulate the graded loading of the subgrade.

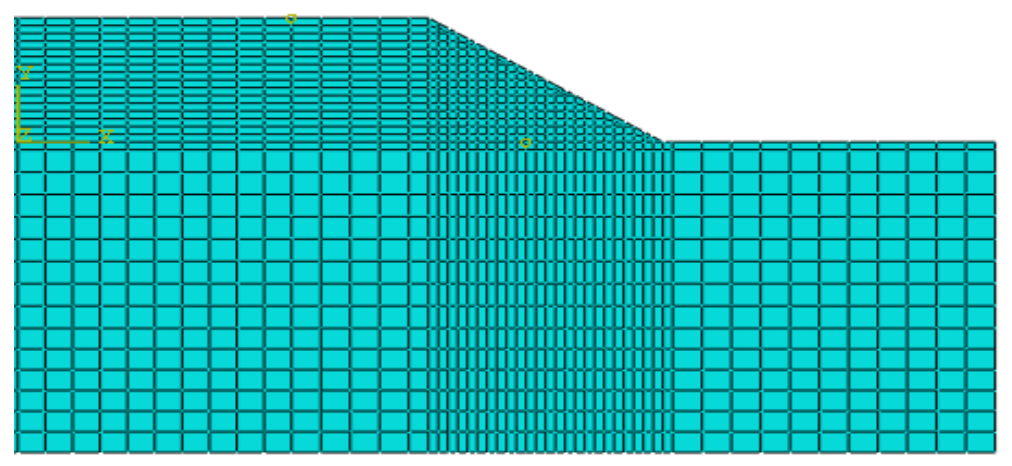

Figure 5. Finite element mesh diagram of subgrade.

\section{Results and Discussion}

\subsection{Foundation Surface Settlement}

\subsubsection{Plan A}

Figure 6 shows that the foundation shows settlement within the range of the subgrade load, and the curve is S-shaped. Before the cross point (not at the foot of the embankment slope), the settlement value increases as the number of layers filled in the roadbed increases. At the beginning of the filling process, the maximum settlement value is not located at the center of the roadbed. As the roadbed is filled, the maximum settlement value gradually moves inward. After the eighth layer is filled, the maximum settlement is transferred to roughly the center of the roadbed. After 15 years, the maximum settlement reaches $468.59 \mathrm{~mm}$. After the cross point, the settlement value first increases and then decreases throughout this process.

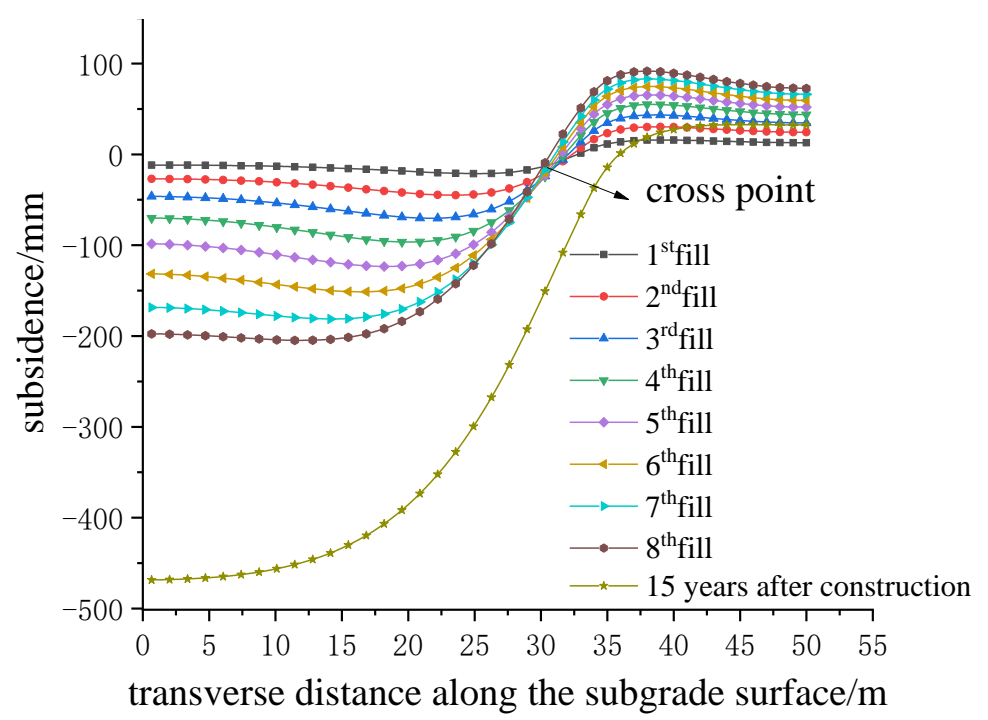

Figure 6. Plan A: total settlement curve of foundation surface.

\subsubsection{Plan B}

Figure 7a shows the ground surface settlement of the wide subgrade surface under Plan B. With an increase in the number of filling layers, the surface of the foundation of the old road is lifted upward. The interaction between the old and the new roadbed affects the characteristics of the old roadbed. However, the ground surface in the area between the 
two cross points is also affected by the new subgrade load and descent. After 15 years, the maximum settlement reaches $475.74 \mathrm{~mm}$.

Figure $7 \mathrm{~b}$ shows the settlement of foundation due to widening under Plan B. The settlement curve of the foundation is V-shaped. The maximum settlement point is located at the center of gravity of the new roadbed. The maximum settlement is $250.92 \mathrm{~mm}$. As the number of layers increases, the settlement at the center of gravity of the new roadbed increases gradually but the increasing range decreases, which indicates that the ground surface tends to be stable.

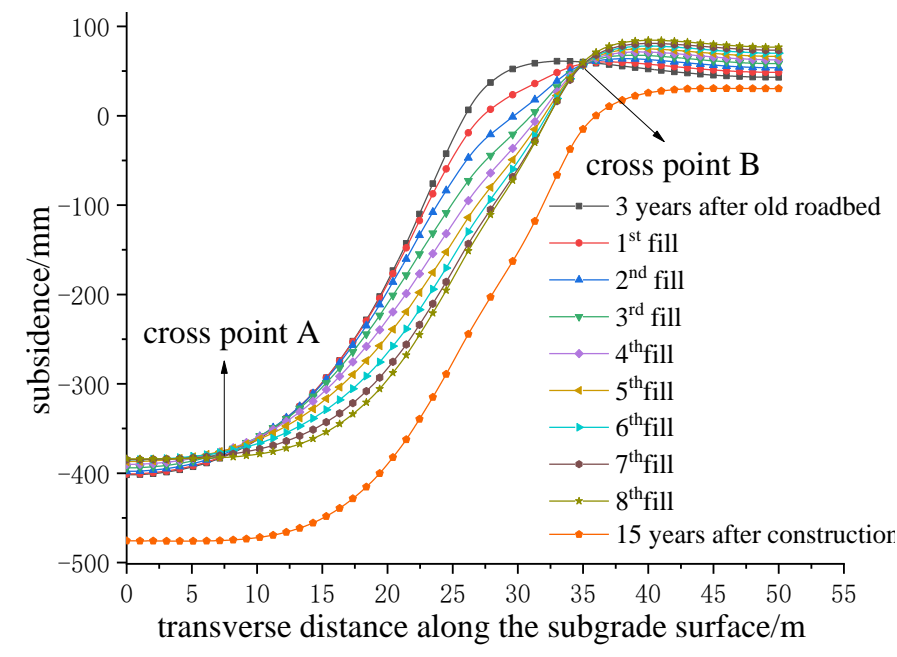

(a)

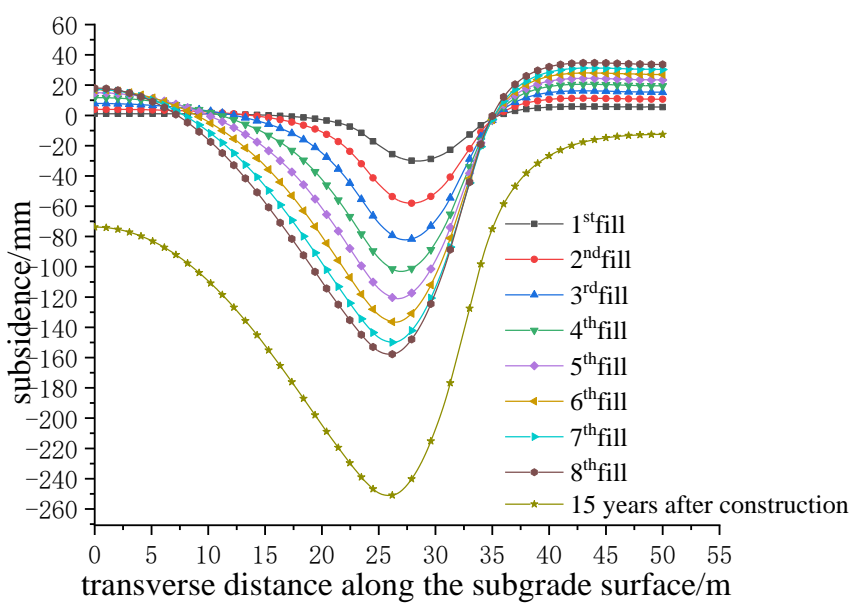

(b)

Figure 7. Plan B: foundation surface settlement. (a) Total settlement curve of foundation surface; (b) settlement of foundation due to widening.

\subsubsection{Plan C}

Figure 8a shows the settlement curve of the wide subgrade surface under Plan C. When the old subgrade is widened, the old subgrade is affected by the new subgrade force. The center of the old subgrade is uplifted on the foundation surface. When the widened subgrade is raised as a whole, the surface of the subgrade descends under the influence of the load of the new subgrade. The dynamic evolution of land subsidence is much more complicated in the case of this plan. After 15 years, the maximum settlement reaches $476.06 \mathrm{~mm}$. Figure $8 \mathrm{~b}$ shows the settlement of the foundation due to widening under Plan C. As the number of layers increases, the settlement increases gradually, but the increasing range decreases and the maximum settlement point moves to the left. The maximum settlement is $349.28 \mathrm{~mm}$.

Figure 9 shows the total settlement of the foundation surface under three working conditions. There is no obvious difference in the settlement curve of the foundation surface in three ways. At the center of the existing road, the settlement value of the foundation surface of Plan A is slightly lower than that of Plans B or C. At $18 \mathrm{~m}$ from the center of the road, the surface settlement values of the three schemes began to approach, and the curves completely overlapped at the foot of the embankment slope. This shows that the construction of roads with different construction methods has little effect on the settlement of the foundation surface. 


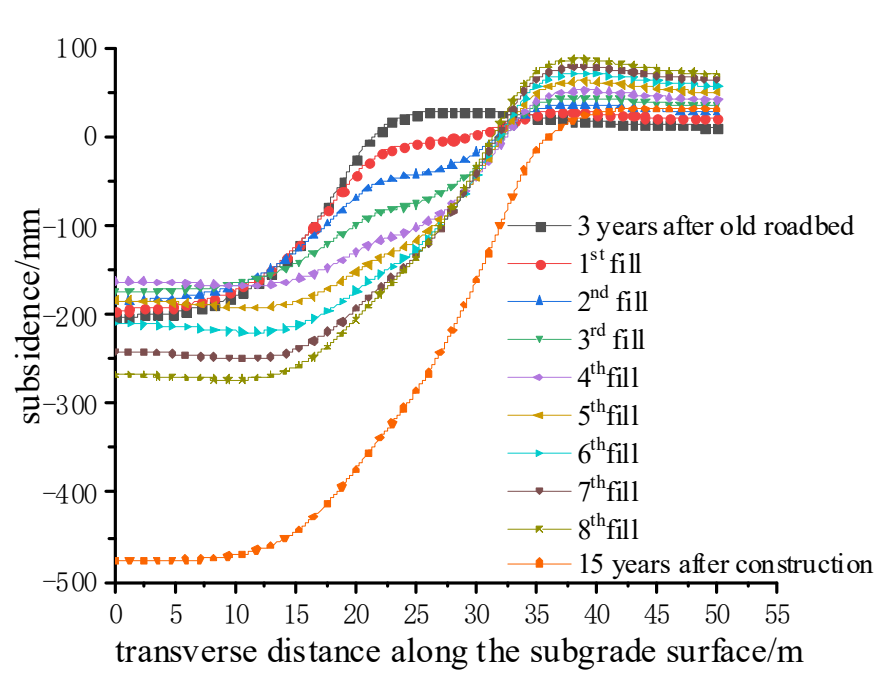

(a)

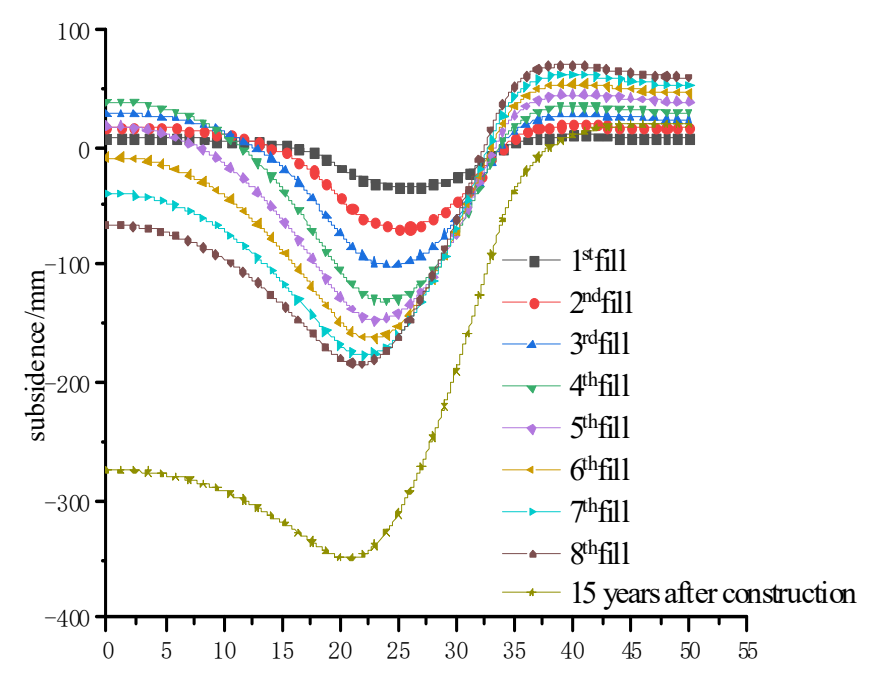

transverse distance along the subgrade surface $/ \mathrm{m}$

(b)

Figure 8. Plan C: foundation surface settlement. (a) Total settlement curve of foundation surface; (b) settlement of foundation due to widening.

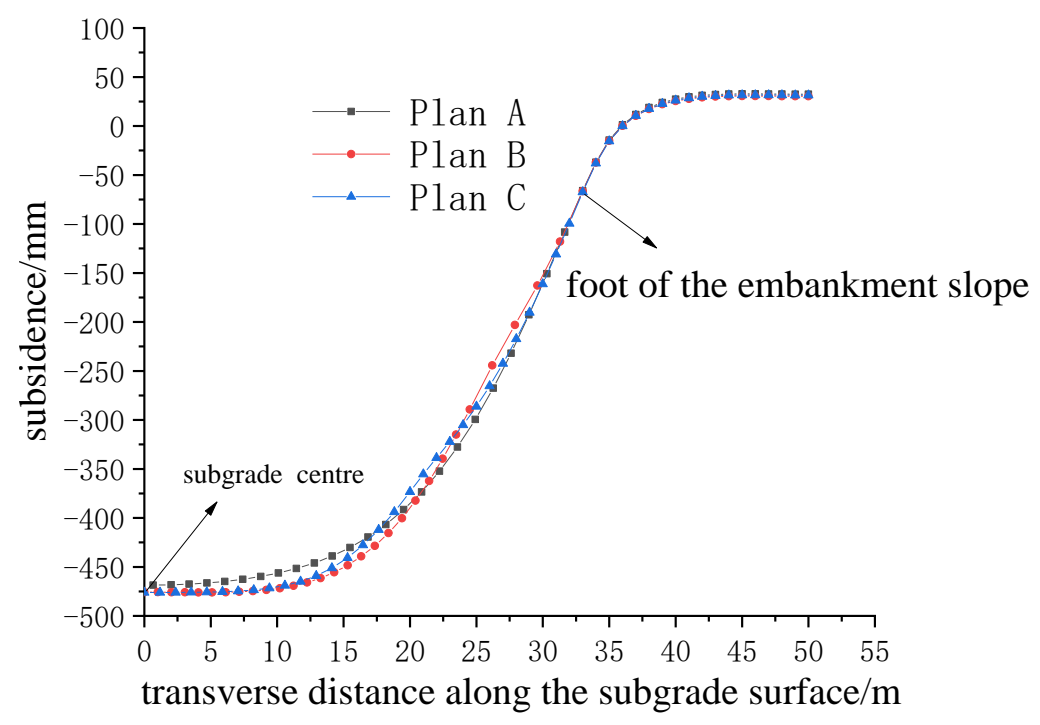

Figure 9. Total settlement of foundation surface under three working conditions.

\subsection{Lateral Displacement of Subgrade Slope Foot}

\subsubsection{Lateral Displacement of New Subgrade Slope Foot}

Figure 10 shows the lateral displacement distribution at the foot of the new embankment slope under three plans. The lateral displacement distribution curves of the three plans are similar in the following aspects: all of them are offset outward, the lateral displacement of mucky clay is larger than that of silty clay, and the maximum lateral displacement is $5 \mathrm{~m}$ below the surface. The road construction mode does not appear to significantly affect the location of the maximum lateral displacement at the foot of the slope. After 15 years, the lateral displacement of mucky clay is much smaller than that of the eighth layer. The maximum lateral displacement of the foot of the new road under the three plans are 139.45, 123.98 , and $134.78 \mathrm{~mm}$ of Plans A-C, respectively. 


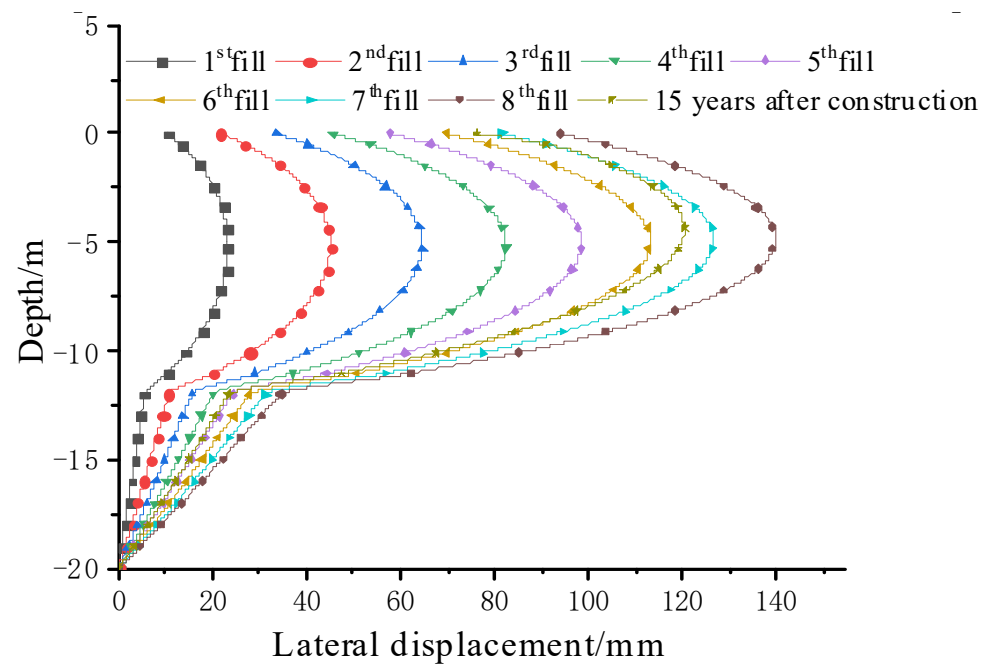

(a)

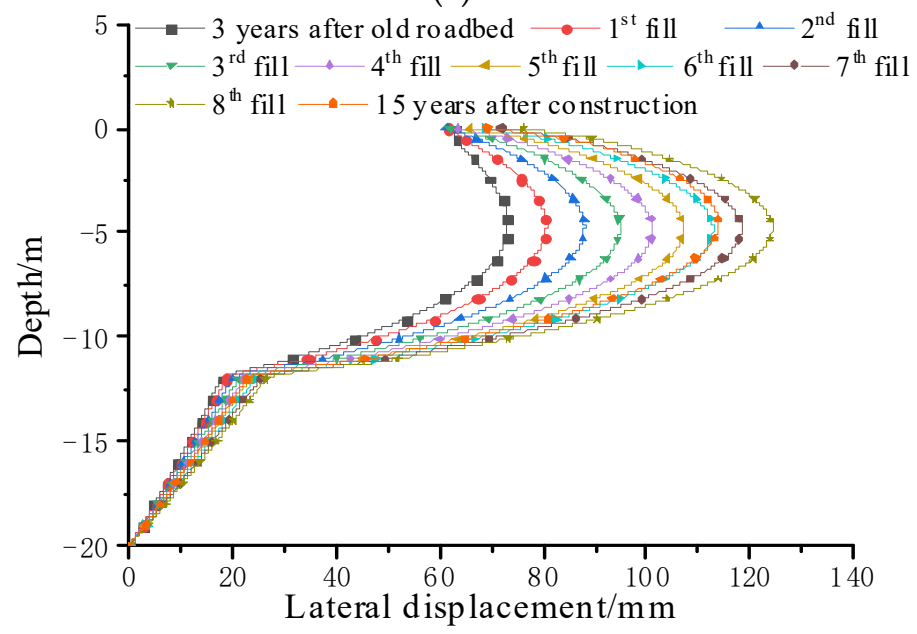

(b)

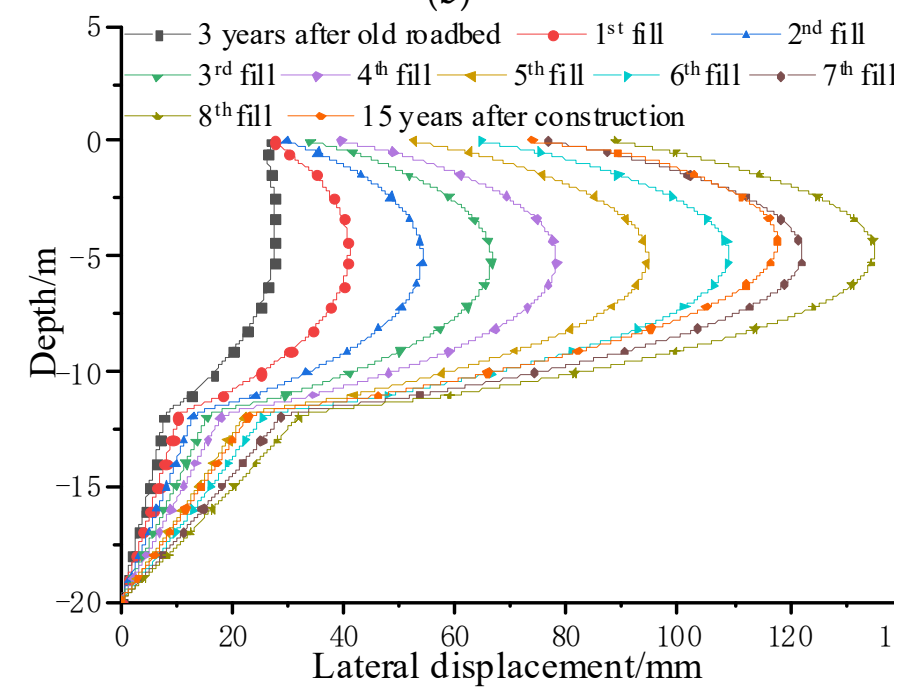

(c)

Figure 10. Lateral displacement of new subgrade slope foot. (a): Plan A; (b): Plan B; (c): Plan C.

Figure 11 shows the lateral displacement of the foot of the new embankment after 15 years under three plans. The maximum lateral displacement is $120.51,113.87$, and $117.82 \mathrm{~mm}$ of Plans A-C, respectively. The lateral displacement of the foot of the Plan B is the smallest compared to Plans A and C. The lateral displacement of the new embankment 
slope loot shows no obvious change, and the lateral displacement distribution and position of the maximum point are almost the same.

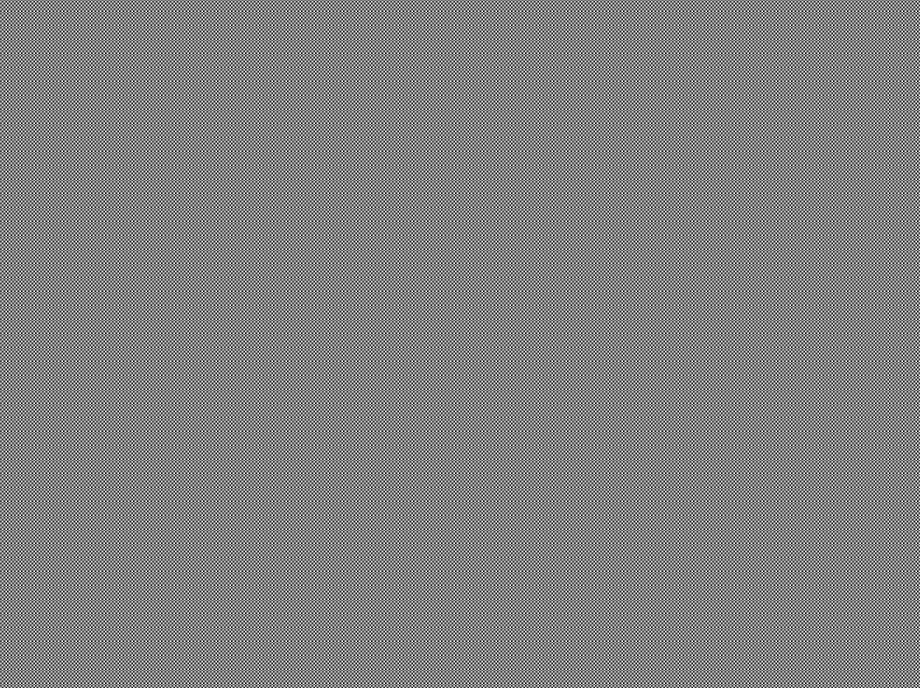

Figure 11. Lateral displacement of new foundation slope foot under three plans after 15 years.

\subsubsection{Lateral Displacement of Old Subgrade Slope Foot}

Figure 12 shows the lateral displacement of the foundation under the foot of the plan B, which differs from that under the foot of the new roadbed. As filling layers increase, the lateral displacement of the foundation under the foot of the old roadbed slope decreases gradually and contracts inward. When the third layer is filled, the lateral displacement of subgrade increases gradually. After the eighth layer is filled, the maximum lateral displacement is $136.92 \mathrm{~mm}$. After 15 years, the lateral displacement of subgrade under the foot of the old subgrade slope decreases gradually. The range of lateral displacement is $124.81,114.81,136.92,127.44 \mathrm{~mm}$.

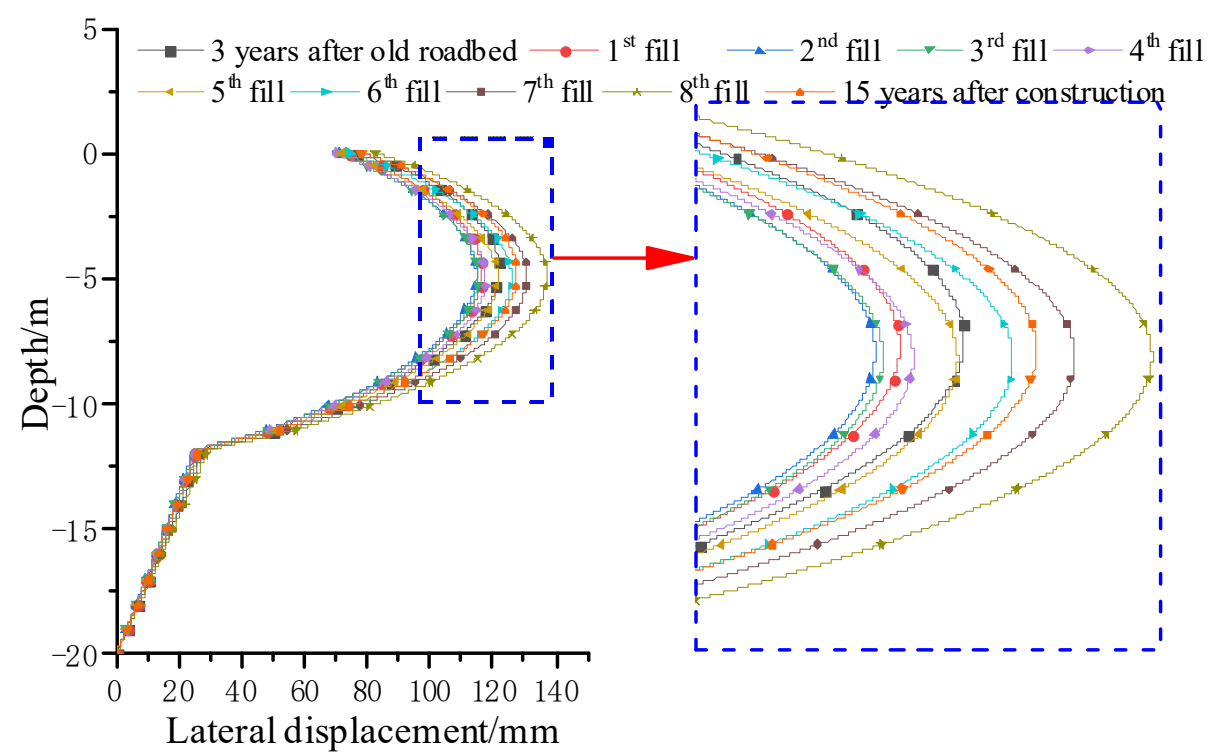

Figure 12. Plan B: lateral displacement of old subgrade slope foot.

Figure 13 shows the lateral displacement of the foundation at the foot of the old roadbed slope under Plan C. Compared with Plan B, the lateral displacement shows the same trend. The maximum lateral displacement is $124.81 \mathrm{~mm}$ at the eighth layer. After 15 years, the lateral displacement retracts inward, and the maximum lateral displacement 
is $104.54 \mathrm{~mm}$. The range of lateral displacement is $70.05,42.58,124.81,104.54 \mathrm{~mm}$. In contrast, the curve of lateral displacement of Plan $\mathrm{C}$ begins to increase after the fifth layer is filled; this increase is much larger than that of the Plan B. Figure 14 shows the variation of maximum lateral displacement of the foot of the existing subgrade slope.

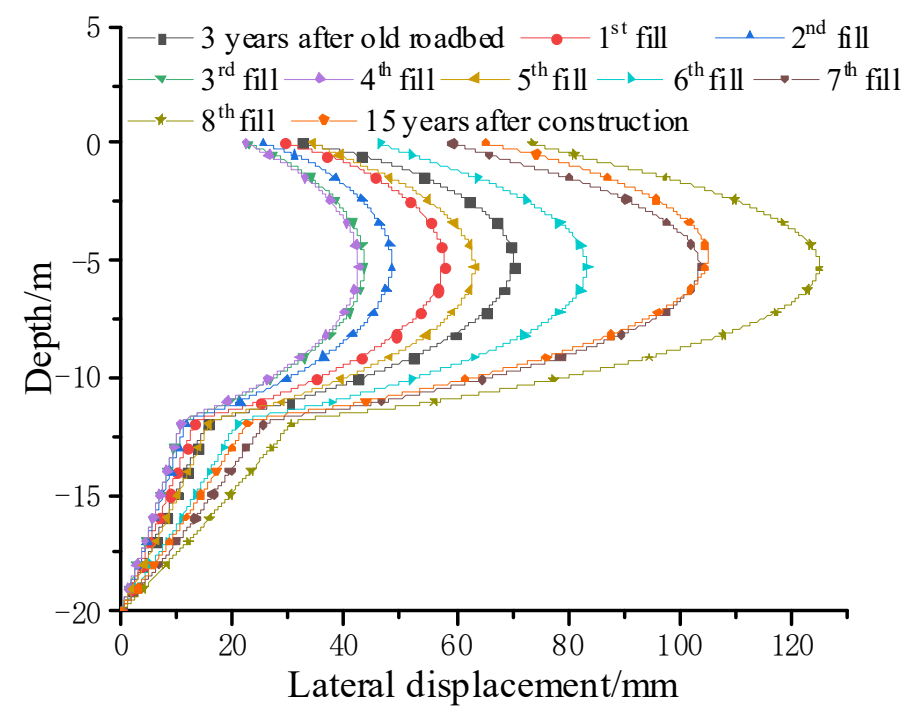

Figure 13. Plan C: lateral displacement of old subgrade slope foot.

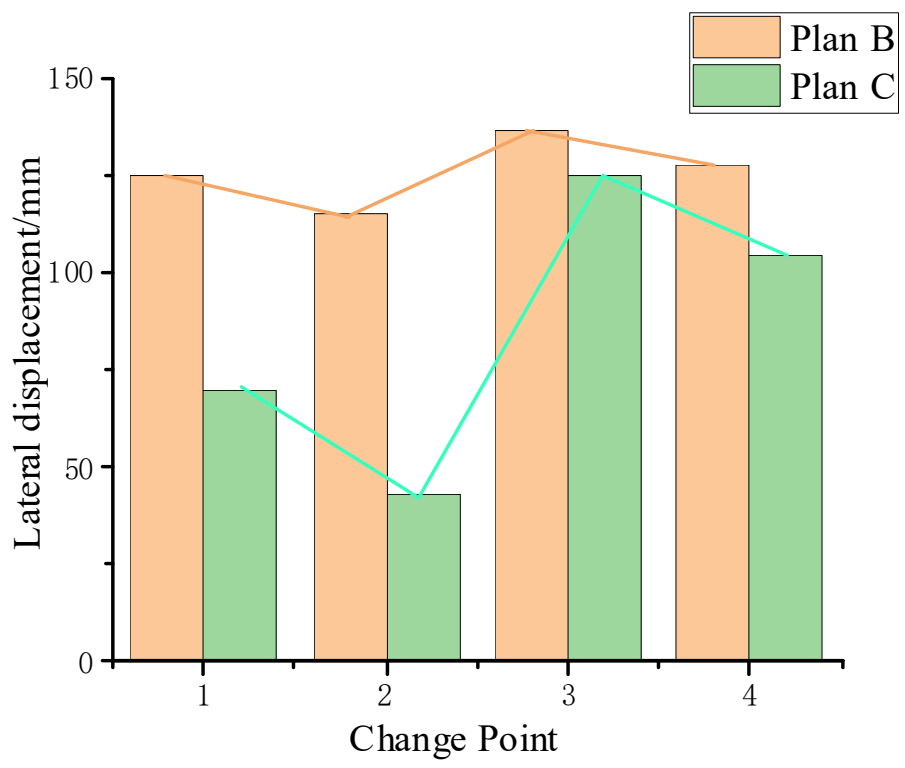

Figure 14. Variation of maximum lateral displacement of foot of old subgrade slope.

\subsection{Subgrade Surface Settlement}

Figure 15 shows the settlement of subgrade surface in different periods under Plan B. The curve changes abruptly at the junction of the old and new roadbeds. After construction, the center of the old roadbed rises upward. After one year of consolidation, the whole roadbed begins to sink. After 10 years, the surface settlement of the roadbed is basically stable, and the rate of decline is slow. After 15 years, the maximum settlement of the subgrade surface appears at the junction of new and old subgrades as $150.84 \mathrm{~mm}$.

Figure 16 shows the surface settlement law of Plan A and C subgrades in different periods. The maximum settlement falls at the center of the roadbed. When the construction is newly finished, the surface settlement conditions of Plans A and C are similar. In the 15 years after the construction, the surface settlement values of Plans A and C are 234.85 
and $297.05 \mathrm{~mm}$, respectively. There is no alternative to Plan C in building the road in this case.

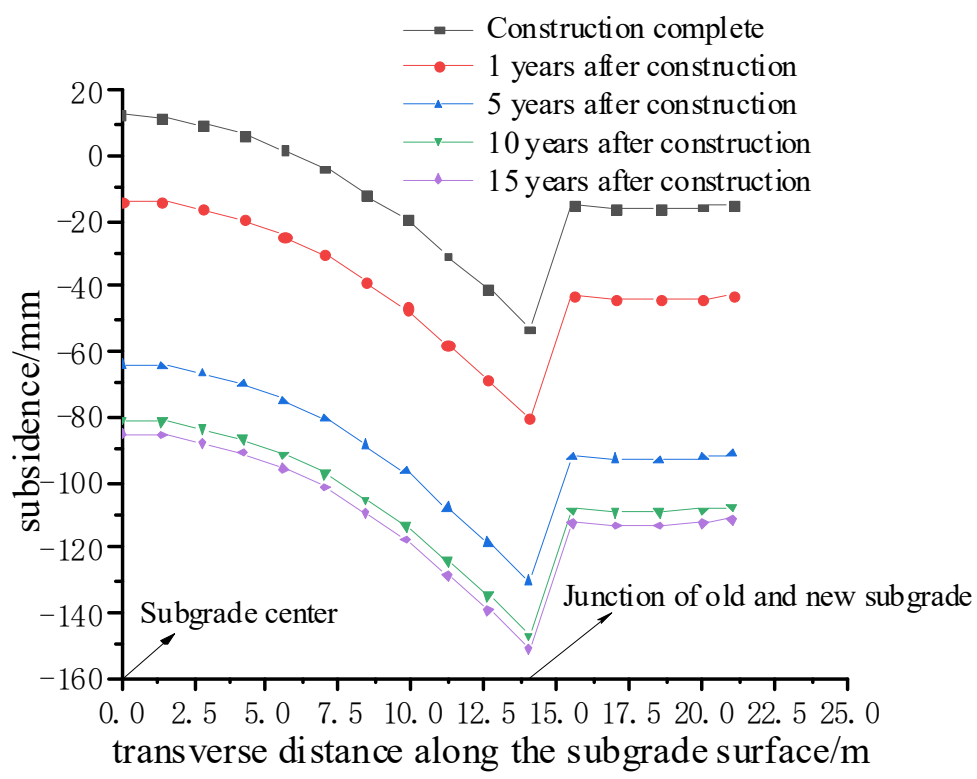

Figure 15. Variation of settlement on top surface of subgrade in different time periods due to widening.

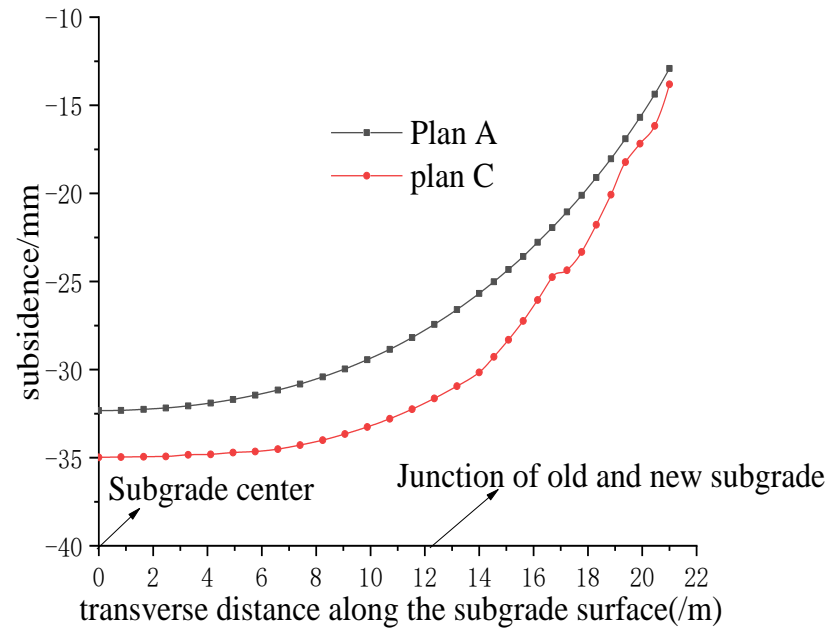

(a)

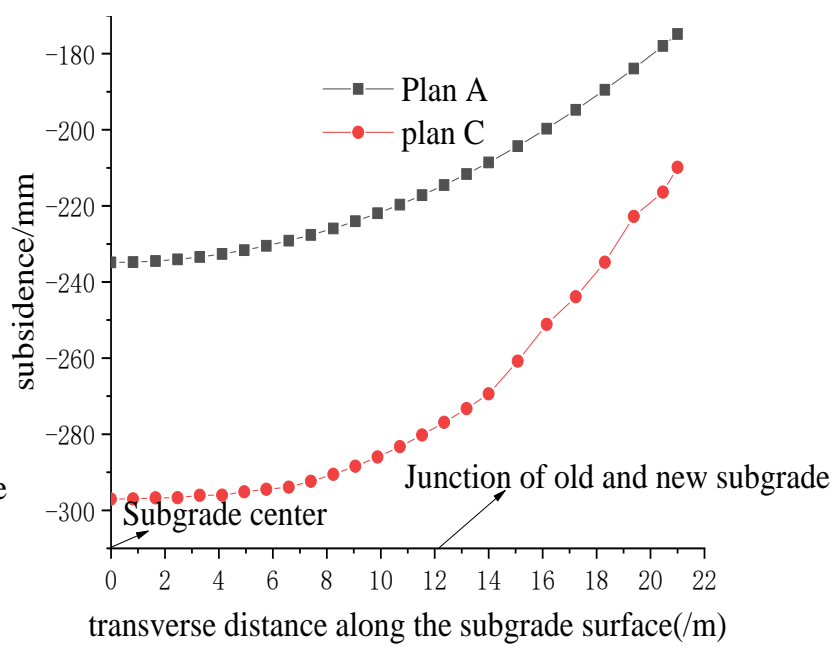

(b)

Figure 16. Plans A and C subgrade surface settlement. (a) Settlement of subgrade surface after construction; (b) settlement of subgrade surface after 15 years of construction.

\section{Conclusions}

Roadway subgrade and foundation settlement characteristics under different construction modes were analyzed in this study by finite element simulation. The conclusions can be summarized as follows.

(1) There is no significant difference in the total settlement of the foundation surface within 15 years after construction. Under the three construction methods, the settlement values of the foundation surface after 15 years are $468.59,475.74$, and $476.06 \mathrm{~mm}$, respectively. The reconstruction and expansion of the old roadbed affects the structure. The construction phase of the old roadbed at the center of the foundation surface 
presents an upward uplift phenomenon. As the number of filling layers increases, the settlement of the ground surface decelerates.

(2) Regardless of the construction method utilized, the maximum horizontal displacement is $5 \mathrm{~m}$ below the surface. The influence of the roadway construction method on the maximum lateral displacement of the slope foot is not significant.

(3) The horizontal displacement at the foot of the new roadbed is close to that of the old one, but the horizontal displacement at the foot of the old one is more complicated than that of the new one.

(4) The surface of subgrade under Plan B stabilizes after 10 years. However, 15 years after construction, the total settlement of the roadbed raised and widened first is much larger than that of the roadbed built directly. In the 15 years after construction, the surface settlement values of Plans A and C are $\mathrm{mm}$ and $297.05 \mathrm{~mm}$, respectively.

Compared with Plans A and B, Plan C produces greater disturbance and stronger interaction with the foundation under the old roadbed. Therefore, Plan $C$ should not be used when it is not necessary. Choosing a suitable construction method can avoid major damage to the road. This article provides practical value for building roads on soft soil foundations.

Author Contributions: Conceptualization, K.L. and W.X.; formal analysis, analysis and writing, K.L; writing and review, W.X. and L.Y.; methodology, K.L. All authors have read and agreed to the published version of the manuscript.

Funding: The research in this paper was supported by the Science and Technology Project of the Department of Transportation of Heilongjiang Province (2019HLJ0073).

Institutional Review Board Statement: Not applicable.

Informed Consent Statement: Not applicable.

Data Availability Statement: Not applicable.

Acknowledgments: The research in this paper was supported by the Science and Technology Project of the Department of Transportation of Heilongjiang Province (2019HLJ0073).

Conflicts of Interest: The authors declare no conflict of interest relevant to this work.

\section{References}

1. Gao, X.; Liu, S.Y.; Shi, M.L. Key problems in widening expressway subgrade on soft soil foundation. J. Highw. Transp. Res. Dev. 2004, 2, 29-33. [CrossRef]

2. Yu, H.; Wang, Y.; Zou, C.; Wang, P.; Yan, C. Study on subgrade settlement characteristics after widening project of highway built on weak foundation. Arab. J. Sci. Eng. 2017, 42, 3723-3732. [CrossRef]

3. Chen, Y.; Cai, Y.; Cao, Z. Predicting postconstruction settlements generated by moving traffic on highways built on soft soil in china using Mechanistic-Empirical design method. J. Transp. Eng. Part. B Pavements 2019, 145, 05019001. [CrossRef]

4. Zou, Z.F.; Huang, Y.F.; Li, J.; Zhang, C. Widening mode and deformation analysis of subgrade in Longitudinal slope-raising section of reconstruction and Extension Project. Subgrade Eng. 2020, 1, 103-108. [CrossRef]

5. Tan, R.; Li, M.; Zhang, J.; Xu, W. Numerical calculation and monitoring analysis of differential settlement of high-speed widening soft soil subgrade. J. Eng. Geol. 2012, 20, 447-452. [CrossRef]

6. El Kamash, W.; Han, J. Displacements of column-supported embankments over soft clay after widening considering soil consolidation and column layout: Numerical analysis. Soils Found. 2014, 54, 1054-1069. [CrossRef]

7. van Meurs, A.N.G.; van den Berg, A.; Venmans, A.A.M.; Van, M.A.; Zwanenburg, C. Embankment widening with the Gap-method. In Proceedings of the Geotechnical Engineering for Transportation Infrastructure: Theory and Practice, Planning and Design, Construction and Maintenance v.2, Amsterdam, The Netherlands, 7-10 June 1999; pp. 1133-1138.

8. Forshman, J.; Uotinen, V.M. Synthetic reinforcement in the widening of a road embankment on soft ground. In Proceedings of the Geotechnical Engineering for Transportation Infrastructure: Theory and Practice, Planning and Design, Construction and Maintenance v.3, Amsterdam, The Netherlands, 1 January 1999.

9. Masaki, K.; Kenji, M. External stability of group column type deep mixing improved ground under embankment loading. Soils Found. 2006, 46, 323-340.

10. Watanabe, K.; Sato, T.; Kudo, A.; Shimada, T.; Morikawa, Y.; Takahashi, H. Proposal of constructional countermeasures for the widening of embankments with a focus on their high stability. Q. Rep. RTRI 2016, 57, 183-190. [CrossRef]

11. Ozer, A.T. Laboratory study on the use of EPS-block geofoam for embankment widening. Geosynth. Int. 2016, 23, 71-85. [CrossRef] 
12. Phutthananon, C.; Jongpradist, P.; Jamsawang, P. Influence of cap size and strength on settlements of TDM-piled embankments over soft ground. Mar. Georesources Geotechnol. 2020, 38, 686-705. [CrossRef]

13. Li, M.; Fang, W.; Han, J.; Wei, L. Benefits of geosynthetic reinforcement in widening of embankments subjected to foundation differential settlement. Geosynth. Int. 2014, 21, 321-332. [CrossRef]

14. Jiang, X.; Geng, J.Y.; Qiu, Y.J. Comparison of mechanical behavior of Expressway subgrade widening on soft soil ground with high groundwater table. J. China Foreign Highw. 2013, 33, 18-23. [CrossRef]

15. Allersma, H.G.B.; Ravenswaay, L.; Vos, E. Investigation of Road Widening on Soft Soils Using a Small Centrifuge; National Academy Press: Washington, DC, USA, 1994.

16. Jia, B.X.; Liu, F.P.; Zhao, L.; Zhou, L.L.; Li, Z.Y. Factor analysis of differential settlement of new and old subgrade caused by highway reconstruction and expansion. J. Safety Environ. 2020, 20, 67-72. [CrossRef]

17. Jia, N.; Chen, R.P.; Chen, T.M.; Xu, L.X.; Yang, S.H. Theoretical analysis and measurement for widening project of Hang-Yong Expressway. Chin. J. Geotech. Eng. 2004, 6, 755-760. [CrossRef]

18. Zhang, J.H. Research on Deformation Behavior and Differential Settlement Limitation of Expressway Widening Oil Soft Soil Foundation; Southeast University: NanJing, China, 2006. [CrossRef]

19. Zhen, F. Study on Differential Settlement and Control. Technology of Subgrade in Expressway Widening Project; Chang'an University: Xian, China, 2007.

20. Pu, Y.S. Study on allowable differential settlement control standard of new and old subgrade. Highw. Automot. Appl. 2019, 3 , 97-101. [CrossRef]

21. Lu, X.F. Study on Differential Settlement Mechanism and Control. Standard of Widening Subgrade of Changyu Expressway; Harbin Institute of Technology: Haerbing, China, 2019.

22. Zhang, S. Study on Differential Settlement Characteristics and Control. Standards of Subgrade Widening of Yan'an North. Transit. Line; Chang'an University: Xian, China, 2019.

23. Wan, Z. Research on Control. Criterion of Subgrade Settlement on Expressway Widening; Chongqing Jiaotong University: Chongqing, China, 2017.

24. Yu, J.R.; Cheng, X.Q.; Li, F.; Huang, Y.F. Study on settlement characteristics and influencing factors of widening subgrade with lengthwise heightening in reconstruction and extension of roads. Subgrade Eng. 2019, 5, 35-39. [CrossRef]

25. Weng, X.; Zhang, L.J.; Li, L.T.; Guo, Y.J. Model test study on differential settlement control technology of equal widened subgrade. Chin. J. Geotech. Eng. 2011, 33, 159-164.

26. Li, J.Y. Deformation analysis of old road widening project on natural foundation. Eng. Constr. 2017, 31, 719-722. [CrossRef]

27. Jiang, X.; Jiang, Y.; Wu, C.; Wang, Q.; Geng, J.; Qiu, Y. Numerical analysis for widening embankments over soft soils treated by PVD and DJM columns. Int. J. Pavement Eng. 2018, 21, 267-279. [CrossRef]

28. Zhang, L.X. Research on Influence of Differential Settlement of Widening Subgrade on Semi-Rigid Asphalt Pavement; Northeast Forestry University: Haerbing, China, 2014.

29. Liao, G.Y.; Huang, X.M. Application of Abaqus Finite Element Software in Road Engineering, 2rd ed.; Southeast University Press: Nanjing, China, 2014; p. 138.

30. Jiang, X.; Jiang, Y.; Liang, X.J.; Wu, Z.Y.; Qiu, Y. Numerical simulation on deformation behaviors for widened expressway embankment over soft ground. J. Railw. Sci. Eng. 2015, 12, 1039-1046. [CrossRef]

31. Lin, Y. Study on Deformation Behavior and Stability of Widened Embankment of High.-Grade Highway; Jilin University: Jilin, China, 2007. 